\title{
Body Mass Index and Risk of Gastric Cancer in Asian Adults: A Meta-Epidemiological Meta-Analysis of Population-Based Cohort Studies
}

Jong-Myon Bae, MD, PhD

Department of Preventive Medicine, Jeju National University College of Medicine, Jeju, Korea

\begin{abstract}
Purpose
A previous meta-analysis (MA) published in 2009 reported that excess body weight was associated with an increased risk of gastric cancer in non-Asians, but not in Asians. The aim was to conduct a meta-epidemiological MA (MEMA) to evaluate association between excess body weight and the risk of gastric cancer in Asian adults with using the proposed classification of weight by body mass index (BMI) in Asian adults.
\end{abstract}

\section{Materials and Methods}

The selection criteria were population-based prospective cohort studies that measured BMI of cohort participants and evaluated a risk of gastric cancer. Overweight group (OW) and obesity group $(\mathrm{OB})$ were defined as 23.0-24.9 and $\geq 25.0$, respectively. A group only showing results for BMI over 23.0 was defined as overweight and obesity group (OWB). Random effect model was applied if $\mathrm{I}^{2}$ value was over $50 \%$.

\section{Results}

After four new studies were added through citation discovery tools, seven cohort studies with 21 datasets were selected finally for MEMA. The $\mathrm{I}^{2}$ value of OW, OB, and OWB were $76.1 \%, 83.5 \%$, and $97.1 \%$, respectively. Only OWB in men had a $\mathrm{I}^{2}$ value below $50 \%(22.5 \%)$ and showed a statistical significance with inverse association (summary relative risk, 0.79; 95\% confidence interval, 0.77 to 0.81 ).

\section{Conclusion}

This MEMA supported the hypothesis that OW might be a protective factor in gastric cancer risk in Asian adults. It will be necessary to conduct additional cohort studies with lengthening follow-up periods and re-analyzing the effect of overweight and obesity classified by the Asian criteria.

\author{
Correspondence: Jong-Myon Bae, MD, PhD \\ Department of Preventive Medicine, \\ Jeju National University College of Medicine, \\ 102 Jejudaehak-ro, 102 Jejudaehang-ro, \\ Jeju 54987, Korea \\ Tel: 82-64-755-5567 \\ Fax: 82-64-725-2593 \\ E-mail: jmbae@jejunu.ac.kr \\ Received May 3, 2019 \\ Accepted August 7, 2019 \\ Published Online August 12, 2019
}

\section{Key words}

Obesity, Overweight, Gastric neoplasms, Systematic review, Meta-analysis

\section{Introduction}

Gastric cancer is one of the most common cancers globally [1]. And the highest incidence and mortality rates among both men and women are found in Asian countries, especially in Japan, Korea and China [2,3]. Several risk factors in gastric cancer including Helicobacter pylori infection, smoking, salt-preserved foods and dietary nitrite have been known well [4].
As obesity is the fastest growing disease worldwide $[5,6]$, the evidences and mechanisms of obesity-induced gastrointestinal neoplasia have been suggested $[7,8]$. There were several meta-analyses for evaluating the association between body mass index (BMI, $\mathrm{kg} / \mathrm{m}^{2}$ ) as level of body weight and risk of gastric cancer [9-12]. Among them, Renehan et al. in 2008 [9] reported the association between obesity and risk of gastric cancer had not a statistical significance. But Turati et al. [11] and Chen et al. [12] in 2013 reported that overweight as well as obesity were strongly related to risk of gastric car- 
Table 1. Summary of the extracted information of seven cohort studies of Asian adults

\begin{tabular}{|c|c|c|c|c|c|c|c|c|}
\hline Study & Nation & $\begin{array}{c}\text { Reference } \\
\text { of BMI }\end{array}$ & $\begin{array}{l}\text { Sex/ } \\
\text { Site }\end{array}$ & Category & $\begin{array}{l}\text { Range } \\
\text { of BMI }\end{array}$ & RR & $95 \%$ CI & Database \\
\hline \multirow{6}{*}{ Kuriyama et al. (2005) [15] } & Japan & 18.5 to 22.9 & $\mathrm{M}$ & OWB & $25.0-27.4$ & 1.01 & $0.74-1.37$ & a \\
\hline & & & M & OWB & 27.5-29.9 & 0.96 & $0.56-1.65$ & $\mathrm{~b}$ \\
\hline & & & M & OWB & $\geq 30.0$ & 1.13 & $0.53-2.41$ & c \\
\hline & & & W & OWB & $25.0-27.4$ & 1.09 & $0.76-1.86$ & d \\
\hline & & & W & OWB & $27.5-29.9$ & 1.80 & $1.06-3.05$ & $\mathrm{e}$ \\
\hline & & & W & OWB & $\geq 30.0$ & 0.79 & $0.29-2.17$ & $\mathrm{f}$ \\
\hline \multirow[t]{2}{*}{ Tanaka et al. (2007) [19] } & Japan & -20.2 & M & OWB & $\geq 22.2$ & 0.79 & $0.77-0.80$ & $\mathrm{~g}$ \\
\hline & & & W & OWB & $\geq 22.2$ & 0.82 & $0.79-0.84$ & $\mathrm{~h}$ \\
\hline \multirow[t]{2}{*}{ Persson et al. (2008) [18] } & Japan & -19.9 & W & OW & $20.0-24.9$ & 0.82 & $0.61-1.11$ & $\mathrm{i}$ \\
\hline & & & W & OB & $\geq 25.0$ & 0.74 & $0.53-1.04$ & $\mathrm{j}$ \\
\hline \multirow[t]{6}{*}{ Jee et al. (2008) [21] } & Korea & 20.0 to 22.9 & $\mathrm{M}$ & OW & $23.0-24.9$ & 0.93 & $0.88-0.99$ & $\mathrm{k}$ \\
\hline & & & $\mathrm{M}$ & OB & $25.0-29.9$ & 1.02 & $1.01-1.03$ & 1 \\
\hline & & & M & OB & $\geq 30.0$ & 1.22 & $1.04-1.45$ & $\mathrm{~m}$ \\
\hline & & & W & OW & $23.0-24.9$ & 1.11 & $1.00-1.25$ & $\mathrm{n}$ \\
\hline & & & W & OB & $25.0-29.9$ & 1.04 & 1.04-1.05 & o \\
\hline & & & W & $\mathrm{OB}$ & $\geq 30.0$ & 0.93 & $0.80-1.11$ & $\mathrm{p}$ \\
\hline Liu et al. (2016) [22] & China & 18.5 to 22.9 & W & OB & $\geq 27.5$ & 1.14 & $0.75-1.73$ & q \\
\hline \multirow[t]{2}{*}{ Fan et al. (2017) [23] } & China & 20.33 to 21.76 & C & OWB & $\geq 23.1$ & 0.94 & $0.94-0.95$ & $\mathrm{r}$ \\
\hline & & & $\mathrm{N}$ & OWB & $\geq 23.1$ & 0.61 & $0.59-0.63$ & $\mathrm{~s}$ \\
\hline \multirow[t]{2}{*}{ Wang et al. (2017) [24] } & Singapore & -27.4 & $\mathrm{C}$ & $\mathrm{OB}$ & $\geq 27.5$ & 1.85 & $1.08-3.13$ & $\mathrm{t}$ \\
\hline & & & $\mathrm{N}$ & $\mathrm{OB}$ & $\geq 27.5$ & 1.27 & $0.93-1.72$ & $\mathrm{u}$ \\
\hline
\end{tabular}

$\mathrm{BMI}$, body mass index $\left(\mathrm{kg} / \mathrm{m}^{2}\right)$; $\mathrm{RR}$, relative risk; $\mathrm{CI}$, confidence interval; $\mathrm{M}$, men; $\mathrm{OWB}$, overweight and obesity; $\mathrm{W}$, women;

$\mathrm{OW}$, overweight; $\mathrm{OB}$, obesity; $\mathrm{C}$, cardia; $\mathrm{N}$, non-cardia.

\begin{tabular}{|c|c|c|c|c|}
\hline Databases in Table 1 & & & $\mathrm{ES}(95 \% \mathrm{Cl})$ & Weight (\%) \\
\hline \multicolumn{5}{|l|}{ Men } \\
\hline $\mathrm{a}$ & & & $1.01(0.74-1.37)$ & 16.89 \\
\hline$b$ & & & $0.96(0.56-1.65)$ & 6.48 \\
\hline c & & & $1.13(0.53-2.41)$ & 3.45 \\
\hline g & $\cdot$ & & $0.79(0.77-0.80)$ & 73.18 \\
\hline Subtotal $\left(I^{2}=22.5 \%, p=0.276\right)$ & & & $0.84(0.73-0.97)$ & 100 \\
\hline \multicolumn{5}{|l|}{ Women } \\
\hline d & - & $\rightarrow$ & $1.19(0.76-1.86)$ & 26.42 \\
\hline e & & $\longrightarrow$ & $1.80(1.06-3.05)$ & 23.49 \\
\hline$f$ & $\rightarrow$ & & $0.79(0.29-2.16)$ & 11.58 \\
\hline $\mathrm{h}$ & - & & $0.82(0.79-0.84)$ & 38.51 \\
\hline Subtotal $\left(I^{2}=73.3 \%, p=0.011\right)$ & $\leftarrow$ & $=$ & $1.08(0.72-1.63)$ & 100 \\
\hline $\begin{array}{l}\text { JOTE: Weights are from } \\
\text { andom effects analysis }\end{array}$ & 0.5 & 2.5 & & \\
\hline
\end{tabular}

Fig. 1. Forest plot for estimating the summary effect size (ES) of obesity by sex. CI, confidence interval. 


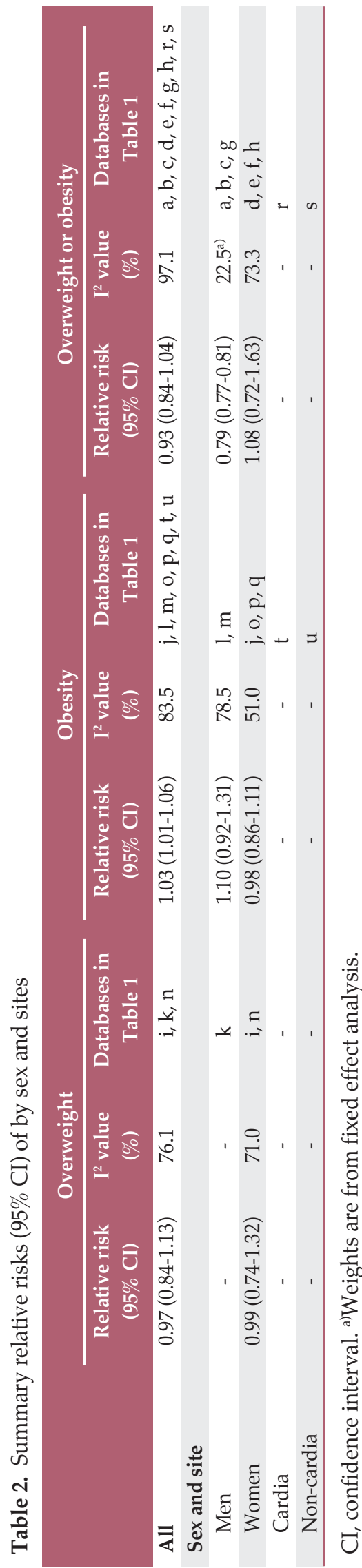

dia adenocarcinoma.

Interestingly, Yang et al. [10] concluded that excess body weight was associated with an increased risk of gastric cancer in non-Asians, but not in Asians. With reviewing of Yang et al. [10], following issues about the conclusion were draw. First, Yang et al. [10] used the World Health Organization classification of weight with overweight $(25.0 \leq \mathrm{BMI}<30.0)$ and obese $(B M I \geq 30.0)$. Thus, it is needed to re-analyze a meta-analysis using Asia-Pacific classification system with overweight $(23.0 \leq \mathrm{BMI}<24.9)$ and obese $(\mathrm{BMI} \geq 25.0)$ [13]. Second, Park et al. [14] among selected studies by Yang et al. [10] should be excluded because it focused not on incidence but on survival in cancer patients. Last, Kuriyama et al. [15] published in 2005 did not be included because of selecting studies that were published through to February 2009. Thus, the aim was to conduct a meta-epidemiological meta-analysis (MEMA) to evaluate association between excess body weight and the risk of gastric cancer in Asian adults.

\section{Materials and Methods}

Because the aim of this was to update and re-analysis the previous meta-analysis by Yang et al. [10], it was necessary to add relevant studies that were published till 30 April 2019. A search list was created through the citation discovery tools (CDT) of 'cited by' provided by PubMed [16] from 4 Asian studies [14,17-19] selected by Yang et al. [10] as well as itself. The selection criteria were population-based prospective cohort studies that measured BMI of cohort participants and evaluated a risk of gastric cancer. As the materials were some published articles, it did not need an ethical consideration.

According to the proposed classification of weight by BMI in Asian adults [13], overweight group (OW) and obesity group (OB) were defined as 23.0-24.9 and $\geq 25.0$, respectively. A group only showing results for BMI over 23.0 was defined as "overweight and obesity group" (OWB). For each study, the relative risk (RR) in group showing the most closely approximated range of BMI was extracted. In case not using the normal range of BMI (18.5-22.9) as the reference, the inverse RR was calculated. The logarithm relative risk (logRR) and its standard error of $\log R R$ (SElogR) of each study was calculated from the extracted RR and 95\% confidence intervals $(\mathrm{CI})$.

Heterogeneity of selected articles was assessed with $\mathrm{I}^{2}$ value $(\%)$. A random effect model was used when $\mathrm{I}^{2}$ value was above $50 \%$ and if not, fixed effect model was used [20]. Subgroup analyses were conducted by three defined groups (OW, OB, and OWB) and sex (men and women). Publication bias was evaluated by Egger's test and Begg's test. The level 
Table 3. Summary table for summary relative risk (and 95\% confidence intervals) of stomach cancer by sex group in four previous systematic reviews

\begin{tabular}{llll} 
Study & BMI & Men & Women \\
\hline Renehan et al. [9] & 5 Unit & $0.97(0.88-1.06)$ & $1.04(0.90-1.20)$ \\
\hline Yang et al. [10] & $25-29$ & $1.10(1.03-1.08)$ & $1.12(0.90-1.40)$ \\
& $\geq 30$ & $1.41(1.08-1.83)$ & $1.06(0.89-1.51)$ \\
\hline & $\geq 25$ & $1.22(0.96-1.55)$ & $1.13(0.65-1.94)$ \\
\hline Turati et al. [11] & $25-29$ & $2.13(1.63-2.78)$ & $1.59(1.20-2.09)$ \\
& $\geq 30$ & $2.17(1.56-3.01)$ & $2.28(1.64-3.18)$ \\
& 5 Unit & $1.13(1.09-1.17)$ & $1.08(0.97-1.20)$ \\
\hline Chen et al. [12] & $25-29$ & $1.07(1.01-1.03)$ & $0.99(0.89-1.11)$ \\
& $\geq 30$ & $1.12(1.00-1.24)$ & $1.04(0.93-1.16)$ \\
\hline
\end{tabular}

BMI, body mass index.

of statistical significance was set to 0.05 .

\section{Results}

A total of 254 studies were retrieved using PubMed's CDT. Four studies among them were additionally selected [21-24]. While Oh et al. [17] and Jee et al. [21] shared the database constructed from the National Health Insurance Corporation in Korea, Jee et al. [21] was selected because it had a larger sample size with extended follow-up periods. Finally, 7 cohort studies with 21 datasets were selected for meta-analysis (Table 1) $[15,18,19,21-24]$. Twenty-one datasets were grouped into OW (i, $\mathrm{k}$, and $\mathrm{n}$ in Table 1$), \mathrm{OB}(\mathrm{j}, \mathrm{l}, \mathrm{m}, \mathrm{o}, \mathrm{p}, \mathrm{q}$, $\mathrm{t}$, and $\mathrm{u}$ in Table 1 ) and OWB (a, b, c, d, e, f, g, h, r, and s in Table 1).

The $\mathrm{I}^{2}$ value of $\mathrm{OW}, \mathrm{OB}$, and OWB were $76.1 \%, 83.5 \%$, and $97.1 \%$, respectively. The summary relative risk (sRR) of OB had a statistical significance but lost it with subgroup analyses by sex. Additional subgroup analyses suggested that only OWB in men had a $\mathrm{I}^{2}$ value below $50 \%(22.5 \%)$ and showed a statistical significance with inverse association (sRR, 0.79; 95\% CI, 0.77 to 0.81) (Fig. 1). The p-value of Egger's test and Begg' test for OWB in men were 0.059 and 0.497 , respectively.

\section{Discussion}

While all datasets in $\mathrm{OW}, \mathrm{OB}$ and $\mathrm{OWB}$ showed a huge heterogeneity, BMI over than 23.0 (OWB) in Asian men having the lowest $\mathrm{I}^{2}$ value was inversely associated with risk of gastric cancer. From these findings, the following three inferences could be draw.

Firstly, the different classification of BMI in Asian adults for overweight and obesity could cause a huge heterogeneity, and this might mask a real association between BMI level and risk of gastric cancer in Asian adults. Because only OWB in men having a $\mathrm{I}^{2}$ value below $50 \%$ showed a statistical significance in this MEMA, but not in Yang et al. [10]. Of seven selected studies, three $[15,21,22]$ did conduct to statistical analyses based on the Asian classification.

Secondly, the different classification of BMI for OWB could cause an opposing direction of sRR. While the sRR of OWB overall and OWB in men showed an under 1.0 in this MEMA, these sRRs in Yang et al. [10] were 1.17 (0.88-1.56) in overall and 1.10 (1.03-1.08) in men. The marginal BMI of OWB in Yang et al. [10] and this MEMA were over 25.0 and 23.0, respectively. Thus, it could be explained that a group having BMI between 23.0 and 24.9 might change the direction of sRR. Because this group was defined as OW in this MEMA, and the sRR of OW was less than 1.0 in Table 2, even though not having a statistical significance with $\mathrm{I}^{2}$ values $76.1 \%$. Based on these inferences, it could suggest a hypothesis that OW might be a protective factor in gastric cancer risk in Asian adults.

Lastly, men had higher sRR than women in OB group in Table 2, even though it was not a statistical significance. This finding was also found in Yang et al. [10] and Chen et al. [12] (Table 3). But additional studies are needed to suggest a hypothesis for risk difference between men and women because the $\mathrm{I}^{2}$ values in men and women were $78.5 \%$ and $51.0 \%$.

Thus, it will be necessary to conduct additional cohort studies with lengthening follow-up periods and re-analyzing the effect of overweight and obesity classified by the Asian criteria [25]. In addition, it will be necessary to perform an 
updated MEMA that adds information from further relevant studies by extending the end of search period.

\section{Conflicts of Interest}

Conflict of interest relevant to this article was not reported.

\section{References}

1. Torre LA, Bray F, Siegel RL, Ferlay J, Lortet-Tieulent J, Jemal A. Global cancer statistics, 2012. CA Cancer J Clin. 2015;65:87108.

2. Torre LA, Siegel RL, Ward EM, Jemal A. Global cancer incidence and mortality rates and trends: an update. Cancer Epidemiol Biomarkers Prev. 2016;25:16-27.

3. Jung KW, Won YJ, Kong HJ, Lee ES. Cancer statistics in Korea: incidence, mortality, survival, and prevalence in 2016. Cancer Res Treat. 2019;51:417-30.

4. Choi YJ. Insulin resistance: a hidden risk factor for gastric cancer? Gut Liver. 2019;13:133-4.

5. Smith KB, Smith MS. Obesity statistics. Prim Care. 2016;43:12135.

6. Ogden CL, Yanovski SZ, Carroll MD, Flegal KM. The epidemiology of obesity. Gastroenterology. 2007;132:2087-102.

7. Aleman JO, Eusebi LH, Ricciardiello L, Patidar K, Sanyal AJ, Holt PR. Mechanisms of obesity-induced gastrointestinal neoplasia. Gastroenterology. 2014;146:357-73.

8. Camilleri M, Malhi H, Acosta A. Gastrointestinal complications of obesity. Gastroenterology. 2017;152:1656-70.

9. Renehan AG, Tyson M, Egger M, Heller RF, Zwahlen M. Body-mass index and incidence of cancer: a systematic review and meta-analysis of prospective observational studies. Lancet. 2008;371:569-78.

10. Yang P, Zhou Y, Chen B, Wan HW, Jia GQ, Bai HL, et al. Overweight, obesity and gastric cancer risk: results from a metaanalysis of cohort studies. Eur J Cancer. 2009;45:2867-73.

11. Turati F, Tramacere I, La Vecchia C, Negri E. A meta-analysis of body mass index and esophageal and gastric cardia adenocarcinoma. Ann Oncol. 2013;24:609-17.

12. Chen Y, Liu L, Wang X, Wang J, Yan Z, Cheng J, et al. Body mass index and risk of gastric cancer: a meta-analysis of a population with more than ten million from 24 prospective studies. Cancer Epidemiol Biomarkers Prev. 2013;22:1395-408.

13. WHO Expert Consultation. Appropriate body-mass index for Asian populations and its implications for policy and intervention strategies. Lancet. 2004;363:157-63.

14. Park SM, Lim MK, Shin SA, Yun YH. Impact of prediagnosis smoking, alcohol, obesity, and insulin resistance on survival in male cancer patients: National Health Insurance Corporation Study. J Clin Oncol. 2006;24:5017-24.

15. Kuriyama S, Tsubono Y, Hozawa A, Shimazu T, Suzuki Y, Koizumi $Y$, et al. Obesity and risk of cancer in Japan. Int J Cancer. 2005;113:148-57.

16. Bae JM, Kim EH. Citation discovery tools for conducting adaptive meta-analyses to update systematic reviews. J Prev Med Public Health. 2016;49:129-33.

17. Oh SW, Yoon YS, Shin SA. Effects of excess weight on cancer incidences depending on cancer sites and histologic findings among men: Korea National Health Insurance Corporation Study. J Clin Oncol. 2005;23:4742-54.

18. Persson C, Inoue M, Sasazuki S, Kurahashi N, Iwasaki M, Ye $\mathrm{W}$, et al. Female reproductive factors and the risk of gastric cancer in a large-scale population-based cohort study in Japan (JPHC study). Eur J Cancer Prev. 2008;17:345-53.

19. Tanaka T, Nagata C, Oba S, Takatsuka N, Shimizu H. Prospective cohort study of body mass index in adolescence and death from stomach cancer in Japan. Cancer Sci. 2007;98:1785-9.

20. Harris RJ, Bradburn MJ, Deeks JJ, Harborad RM, Altman DG, Sterne JA. Metan: fixed- and random-effects meta-analysis. Stata J. 2008;8:3-28.

21. Jee SH, Yun JE, Park EJ, Cho ER, Park IS, Sull JW, et al. Body mass index and cancer risk in Korean men and women. Int J Cancer. 2008;123:1892-6.

22. Liu Y, Warren Andersen S, Wen W, Gao YT, Lan Q, Rothman $\mathrm{N}$, et al. Prospective cohort study of general and central obesity, weight change trajectory and risk of major cancers among Chinese women. Int J Cancer. 2016;139:1461-70.

23. Fan JH, Wang JB, Wang SM, Abnet CC, Qiao YL, Taylor PR. Body mass index and risk of gastric cancer: a 30-year followup study in the Linxian general population trial cohort. Cancer Sci. 2017;108:1667-72.

24. Wang Z, Koh WP, Jin A, Wang R, Yuan JM. Composite protective lifestyle factors and risk of developing gastric adenocarcinoma: the Singapore Chinese Health Study. Br J Cancer. 2017;116:679-87.

25. Bae JM. Meta-epidemiology. Epidemiol Health. 2014;36: e2014019. 